Case report

\title{
A rare case of hepatic sub capsular biloma after open cholecystectomy: a case report
}

\section{Karim Ibn Majdoub Hassani*, El Bachir Benjelloun, Abdelmalek Ousadden, Khalid Mazaz and Khalid Ait Taleb}

Address: Department of General Surgery, Universitet Hospital Hassan II, Fes, Morocco

Email: KIMH* - ibnmajdoubkarim@yahoo.fr; EBB - benjelloun19@hotmail.com; AO - aousadden@yahoo.fr; KM - khalid.mazaz@caramail.com; KAT - chufes@menara.ma

* Corresponding author

Received: 25 June 2009 Accepted: 25 August 2009 Published: 15 September 2009

Cases Journal 2009, 2:7836 doi: 10.4076/1757-1626-2-7836

This article is available from: http://jmedicalcasereports.com/jmedicalcasereports/article/view/7836

(C) 2009 Hassani et al.; licensee Cases Network Ltd.

This is an Open Access article distributed under the terms of the Creative Commons Attribution License (http://creativecommons.org/licenses/by/3.0), which permits unrestricted use, distribution, and reproduction in any medium, provided the original work is properly cited.

\begin{abstract}
Bilomas are localized collections of bile occurring usually post-operatively from an injured cystic or bile duct while most bilomas collect in the subhepatic space. We describe a rare case of hepatic subcapsular biloma after open cholecystectomy successfully treated by percutaneous drainage.
\end{abstract}

\section{Introduction}

Bile leak after open or laparoscopic cholecystectomy is usually a result of minor biliary injury, although it can sometimes reveal a major duct injury. It is estimated that biloma originates from the cystic duct in more than $50 \%$ of the cases [1]. Hepatic subcapsular bilomais an exceptional complication after cholecystectomy. We describe a rare case of a 28-year-old woman, presented 2 weeks after open partial cholecystectomy with signs of a rightsided chest pain, dyspnea and cough as a result of subcapsular biloma diagnosed by a computed tomography (CT) and, successfully treated by percutaneous drainage. There are only some cases reported in the literature of this complication after laparoscopic cholecystectomy, but according to our knowledge and from an intensive literature research, this is the first case which has been described after an open cholecystectomy.

\section{Case presentation}

A 28-year-old previously healthy Moroccan woman presented to the emergency department 15 days after open subtotal cholecystectomy for acute cholecystitis with a 5 days history of rightsided chest pain, dyspnea and cough. She had no abdominal pain, no fever, no vomit and no jaundice. The patient was not using any specific medication and her medical history did not suggest any major disease. She had no prior history of abdominal surgery or trauma. She had a difficult partial cholecystectomy due to severe inflammation in the Calot's triangle, large empyema in the gall bladder and, excessive bleeding during difficult dissection between gall bladder and liver bed. Subtotal cholecystectomy was done as the cystic duct could not be isolated. The physical examination revealed a conscious woman who's had a temperature 37 degree $\mathrm{C}$, a pulse rate 90 beats per minute (bpm), a blood pressure 120/70 mm Hg. The abdominal examination revealed a 
right upper scar without abdominal tenderness. There were no palpable masses or liver enlargement. Laboratory data revealed an hematocrit of $41 \%$, an hemoglobin of $12,6 \mathrm{~g} / \mathrm{dl}$, white blood cells of $11,100 / \mathrm{mm}^{3}$ ( $83 \%$ neutrophils), a blood urea of $0,25 \mathrm{~g} / \mathrm{L}$, and a creatinine level of $10 \mathrm{mg} / \mathrm{L}$. Liver enzymes showed a total bilirubin of $13 \mathrm{mg} / \mathrm{L}$ with a direct component of $6 \mathrm{mg} / \mathrm{L}$; SGOT and SGPT were $87 \mathrm{U} / \mathrm{L}$ and $166 \mathrm{U} / \mathrm{L}$, respectively (normal range for SGOT is $17-59$ $\mathrm{U} / \mathrm{L}$ and for SGPT is $21-72 \mathrm{U} / \mathrm{L}$ ). The chest X-ray showed right-sided chest opacity that simulates pleural effusion (Figure 1). Ultrasonography (US) of the abdomen revealed a large unilocular subcapsular fluid-filled collection in the right lobe of the liver with no free intra-abdominal fluid. Thoraco-abdominal computed tomography (CT) confirmed results of US and concluded a large hepatic sub capsular biloma measuring $(21 \mathrm{~cm} \times 16 \mathrm{~cm} \times 14 \mathrm{~cm})$ (Figures 2 and 3). Based on the imaging findings, we made a decision to perform a percutaneous US-guided puncture which removed $2000 \mathrm{ml}$ of bile.

After draining the abscess a drainage catheter was positioned and left in place. The catheter drained more than $500 \mathrm{ml}$ of bile over 5 days and it was removed 2 days later when the output was ceased and, a follow up US showed a near-complete resolution (Figure 4). No complication occurred. We noted that the liver enzymes were normal en days following drainage. The patient was free of any symptoms at the 3 month follow up. A further US, performed after six month later was normal and, did not show any abnormalities.

\section{Discussion}

The term biloma was introduced in 1979 by Gould and Pater to describe a loculated collection located outside the

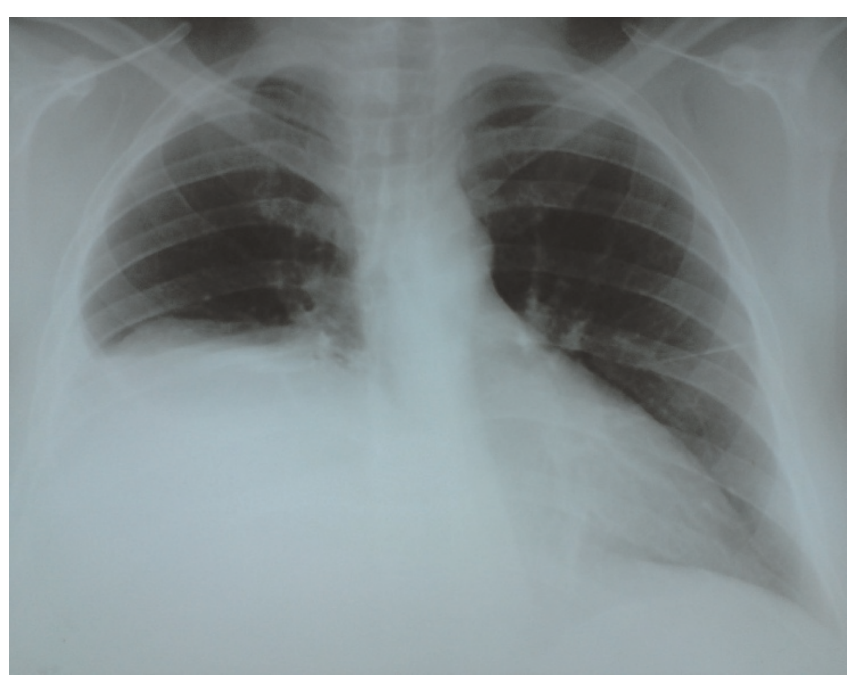

Figure I. Chest X-ray demonstrated a right pleural effusion.

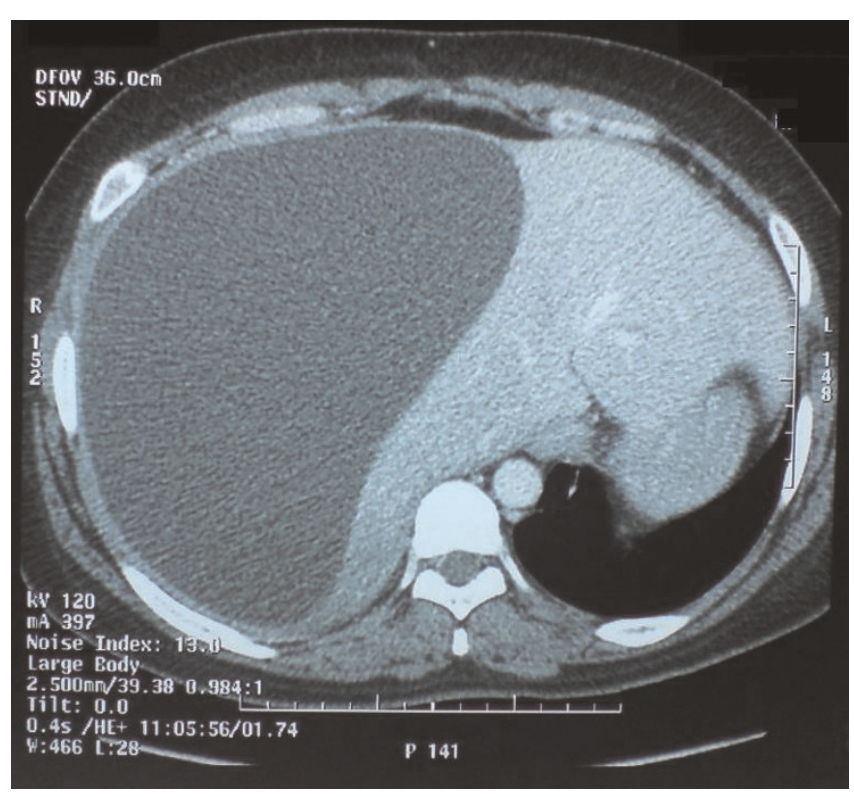

Figure 2. Abdominal CT (axial) demonstrated unilocular subcapsular fluid-filled collection in the right lobe of the liver.

biliary tree. Kuligowska et al. extended the term biloma to include intrahepatic as well as extrahepatic collections of bile. Bilomas mainly result from iatrogenic, traumatic, or spontaneous rupture of the biliary tree [2]. Although bile leakage into the peritoneal cavity is a known complication

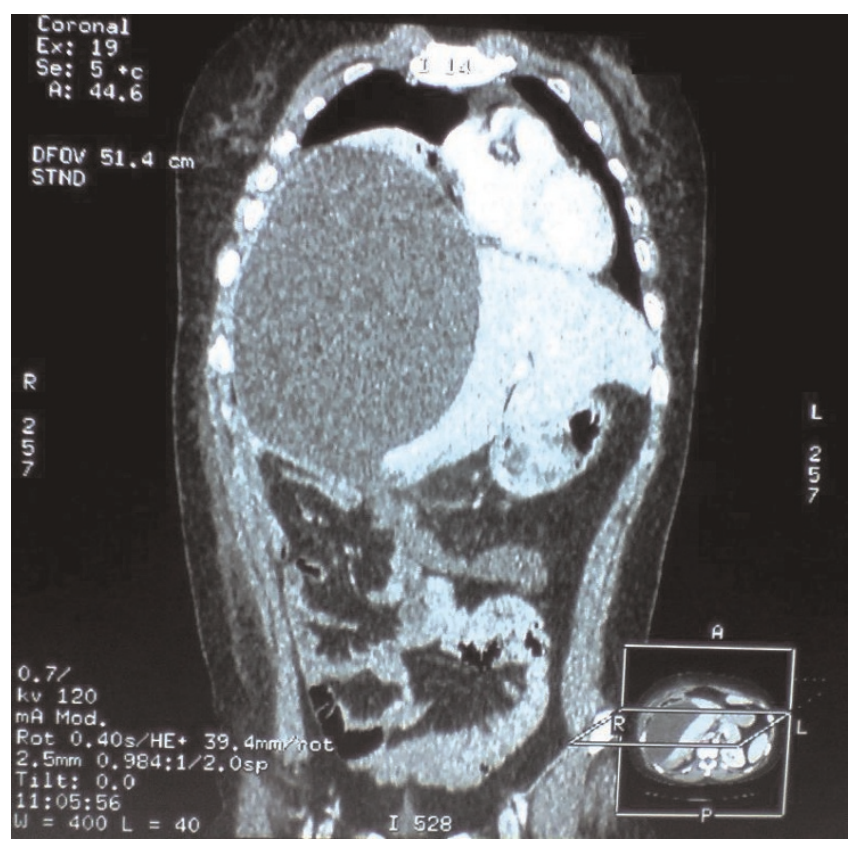

Figure 3. Abdominal CT (coronal) demonstrated unilocular subcapsular fluid-filled collection in the right lobe of the liver. 


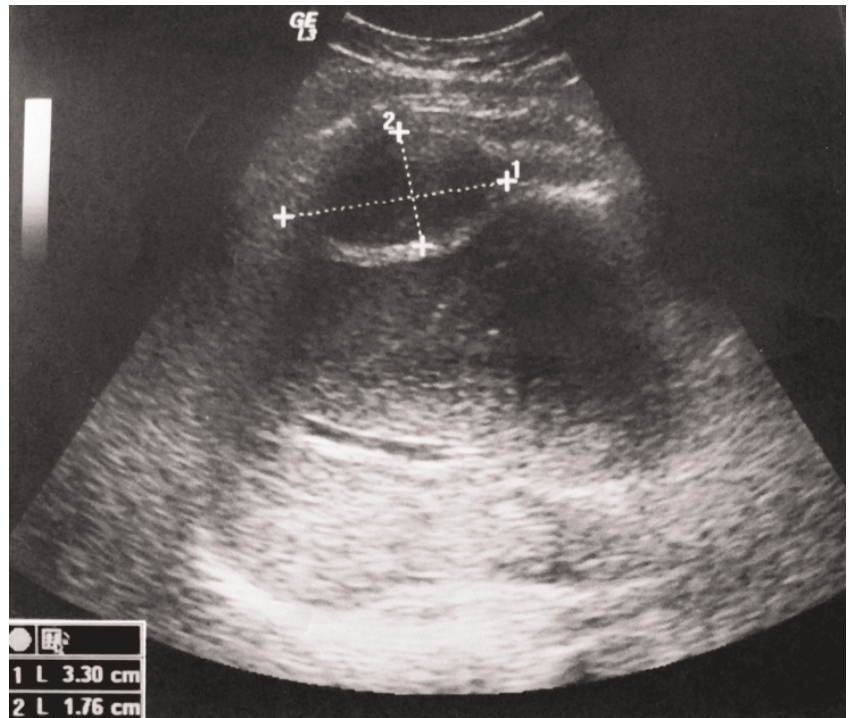

Figure 4. Ultra sonography showed nearly a total vanishing of the biloma, with persistence of a little collection measuring $(3.30 \times 1.76 \mathrm{~cm})$.

of open and laparoscopic cholecystectomy [3], the hepatic subcapsular biloma is an exceptional complication after cholecystectomy. Some authors attribute this complication to a small biliary perforated radical because of the backpressure associated with the high-pressure irrigation used during choledochoscopy [4].

High pressure in the proximal biliary ducts, caused by injection of contrast material, is the reported cause of a hepatic subcapsular biloma after ERCP [5]. We think that the possible etiology for the hepatic subcapsular biloma in our patient is a disruption of a small biliary radical near the gallbladder bed during dissection, because the procedure was technically difficult and the anatomy was not well defined. The right upper quadrant abdominal pain is the constant sign in the patient with subcapsular biloma described in the literature, associated sometimes with nausea and vomiting [4]. Our case was unique that the patient presented with respiratory symptoms without any abdominal signs.

Ultrasound is sensitive for diagnosing bilomas, but the diagnosis of this complication is ideally facilitated by the use of Computed tomography [6], Imaging of the biliary tree should be performed early to determine the location and extent of bile leaks [4]. Hepatic subcapsular biloma can be drained percutaneously with removal of the drainage catheter when the output is minimal [4-7]. Our patient and the three other reported cases of bilomas were managed similarly with US guided percutaneous drainage with a good outcome. To conclude a subcapsular biloma is an exceptional complication of cholecystectomy. Early diagnosis and appropriate percutaneous drainage are the key to manage this rarity.

\section{Consent}

Written informed consent was obtained from the patient for publication of this case report and accompanying images. A copy of the written consent is available for review by the Editor-in-Chief of this journal.

\section{Competing interests}

The authors declare that they have no competing interests.

\section{Authors' contributions}

$\mathrm{KI}$ is a surgeon who was drafting the manuscript and revising it critically for content. $\mathrm{EB}$ and $\mathrm{AO}$ were involved in literature research and were major contributors in writing the manuscript. KM and KA were surgeons treating of the patient and were involved in revising the draft critically for content. All authors read and approved the final manuscript.

\section{References}

I. De Palma GD, Galloro G, Iuliano G, Puzziello A, Persico F, Masone S, Persico G: Leaks from laparoscopic cholecystectomy. Hepatogastroenterology 2002, 49:924.

2. Emmanuel Christoforidis Al: A Single Center Experience in Minimally Invasive Treatment of Postcholecystectomy Bile Leak, Complicated With Biloma Formation. J Surg Res 2007, |41:|7|-|75.

3. Soon SY, Wakefield C, Nixon SJ: Bile leak after laparoscopic cholecystectomy. Br J Surg 2000, 87:56-57.

4. Braithwaite BM, Cabanilla LT, Lilly M: Hepatic subcapsular biloma: a rare complication of laparoscopic cholecystectomy and common bile duct exploration. Curr Surg 2003, 60:196-198.

5. Dupas JL, Mancheron H, Sevenet F, Delamarre J, Delcenserie R, Capron JP: Hepatic subcapsular biloma. An unusual complication of endoscopic retrograde cholangiopancreatography. Gastroenterology 1988, 94: I 225-I 227.

6. Hartle RJ, McGarrity TJ, Conter RL: Treatment of a giant biloma and bile leak by ERCP stent placement. Am J Gastroenterol I993, 88:2II7.

7. McLindon JP, England RE, Martin DF: Causes, clinical features and non-operative management of bile leaks. Eur Radiol 1998, 8:1602. 